\title{
Confirmatory testing of primary aldosteronism with saline infusion test and LC-MS/MS
}

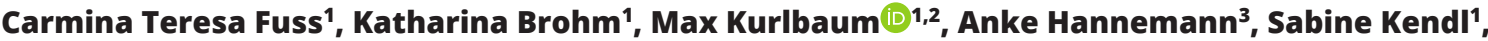 \\ Martin Fassnacht ${ }^{\mathbb{D}}{ }^{1}$, Timo Deutschbein', Stefanie Hahner ${ }^{1}$ and Matthias Kroiss $\mathbb{D}^{1,2,4}$
}

${ }^{1}$ Division of Endocrinology and Diabetes, Department of Internal Medicine I, University Hospital, University of Würzburg, Würzburg, Germany, ${ }^{2}$ Central Laboratory, Core Unit Clinical Mass Spectrometry, University Hospital Würzburg, Würzburg, Germany, ${ }^{3}$ Institute of Clinical Chemistry and Laboratory Medicine, University Medicine Greifswald, Greifswald, Germany, and ${ }^{4}$ Department of Medicine IV, University Hospital Munich, Ludwig-Maximilians-Universität München, Munich, Germany

Correspondence should be addressed to $\mathrm{M}$ Kroiss

Email

Kroiss_M@ukw.de

\section{Abstract}

Objective: Saline infusion testing (SIT) for confirmation of primary aldosteronism (PA) is based on impaired aldosterone suppression in PA compared to essential hypertension (EH). In the past, aldosterone was quantified using immunoassays (IA). Liquid chromatography tandem mass spectrometry (LC-MS/MS) is increasingly used in clinical routine. We aimed at a method-specific aldosterone threshold for the diagnosis of PA during SIT and explored the diagnostic utility of steroid panel analysis.

Design: Retrospective cohort study of 187 paired SIT samples (2009-2018). Diagnosis of PA $(n=103)$ and EH $(n=84)$ was established based on clinical routine workup without using LC-MS/MS values.

Setting: Tertiary care center.

Methods: LC-MS/MS using a commercial steroid panel. Receiver operator characteristics analysis was used to determine method-specific cut-offs using a positive predictive value (PPV) of $90 \%$ as criterion.

Results: Aldosterone measured by IA was on average $31 \mathrm{ng} / \mathrm{L}$ higher than with LC-MS/MS. The cut-offs for PA confirmation were $54 \mathrm{ng} / \mathrm{L}$ for IA (sensitivity: 95\%, 95\% Cl: 89.0-98.4; specificity: 87\%, 95\% Cl: 77.8-93.3; area under the curve (AUC): $0.955,95 \% \mathrm{Cl}$ : 0.924-0.986; PPV: 90\%, 95\% Cl: 83.7-93.9) and 69 ng/L for LC-MS/MS (79\%, 95\% Cl: 69.5-86.1; 89\%, 95\% Cl: 80.6-95.0; 0.902, 95\% Cl: 0.857-0.947; 90\%, 95\% Cl: 82.8-94.4). Other steroids did not improve SIT.

Conclusions: Aldosterone quantification with LC-MS/MS and IA yields comparable SIT-cut-offs. Lower AUC for LC-MS/MS is likely due to the spectrum of disease in PA and previous decision making based on IA results. Until data of a prospective trial with clinical endpoints are available, the suggested cut-off can be used in clinical routine.

\section{Introduction}

Primary aldosteronism (PA) is characterized by an autonomous aldosterone secretion leading to sodium retention, arterial hypertension and hypokalemia (1). PA is the most common endocrine cause of secondary hypertension, with a prevalence between 5 and 13\% in patients with arterial hypertension $(1,2,3)$. The disease is associated with an increased cardiovascular risk and renal complications $(2,4,5)$. Whereas unilateral oversecretion of aldosterone can be cured by adrenal surgery, patients with bilateral disease receive life-long treatment with mineralocorticoid antagonists (1). Therefore, correct diagnosis and subsequent subtype differentiation (c) 2021 The authors Published by Bioscientifica Ltd. Printed in Great Britain

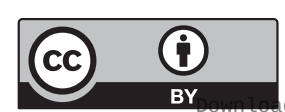

This work is licensed under a Creative Commons Attribution 4.0 International License. 
are crucial for adequate clinical management. The current Clinical Practice Guideline of the Endocrine Society recommends screening by determination of the aldosterone/renin ratio (ARR) (1). Confirmatory testing can be accomplished by using the saline infusion test (SIT), captopril challenge, fludrocortisone suppression, or oral sodium loading (1). All of those tests differ regarding their reported sensitivity, specificity, and reliability; clearcut evidence for one optimal confirmatory test is still lacking $(6,7,8,9)$.

Local expertise, costs, patient compliance and laboratory routine guide the choice of the testing procedure (1). Among the available tests, SIT represents one of the most widely used ones which is most likely explained by its simplicity, safety profile, and cost effectiveness $(10,11)$. Notably, however, cut-off values to rule out PA by SIT are hampered by liabilities of currently used immunoassays (IA), which show low inter-assay agreement particularly in the low range of aldosterone concentration $(12,13,14)$. This appears to be caused (at least in part) by cross-reactivity with other compounds and metabolites $(15,16,17)$, particularly in patients with impaired renal function (18).

Liquid chromatography tandem mass spectrometry (LC-MS/MS) has been introduced into the clinical routine analysis of steroid hormones $(19,20,21)$ due to its higher specificity and is increasingly used for the diagnosis of adrenal diseases $(22,23,24)$. Aldosterone concentrations measured with LC-MS/MS are usually lower than those measured by most IAs $(15,17,25,26$, $27,28)$. Guo et al. recently proposed a LC-MS/MS-specific cut-off for aldosterone during fludrocortisone suppression testing (28). Regarding SIT, however, LC-MS/MS-derived counterparts are still lacking.

The current study aims to establish LC-MS/MS-specific threshold values for aldosterone during SIT and to determine their diagnostic accuracy for the presence of PA in a cohort of 187 SIT performed under standardized conditions at a single tertiary referral center.

\section{Subjects and methods}

\section{Study design, participants and saline infusion testing}

We retrospectively evaluated 236 consecutive patients who underwent SIT for suspected PA at the University Hospital Würzburg between 2009 and 2018. The sample size was hence determined by the availability of biomaterial within this time frame. The investigation was approved by the Ethics committee of the University of Würzburg (20190123 03). SIT was carried out as confirmatory test in patients with suspected PA due to elevated ARR (>20) using a standardized protocol. Before testing, mineralocorticoid antagonists were discontinued for 4 weeks and antihypertensive medication was adapted allowing only calcium channel blockers (e.g. verapamil) and/or alpha receptor antagonists (e.g. urapidil, doxazosin) for at least 1 week. SIT was carried out in a recumbent position in the morning between 08:00 and 10:00 h . Potassium supplementation was administered to avoid hypokalemia during the test. Patients received $2 \mathrm{~L}$ of $0.9 \%$ saline solution intravenously over $4 \mathrm{~h}$. Immediately before saline infusion, as well as after $4 \mathrm{~h}$, serum/plasma samples were taken for measurement of aldosterone, renin and potassium and afterwards stored at $-80^{\circ} \mathrm{C}$.

Forty-nine patients were excluded from the study for the following reasons (Fig. 1): (i) use of antihypertensive medication (beta-blockers, angiotensin-converting enzyme inhibitors, angiotensin receptor blockers) that possibly interferes with test results ( $n=29)$, (ii) insufficient quantity of stored serum samples $(n=8)$, (iii) initial testing repeated (with inconclusive results) $(n=5)$, or (iv)

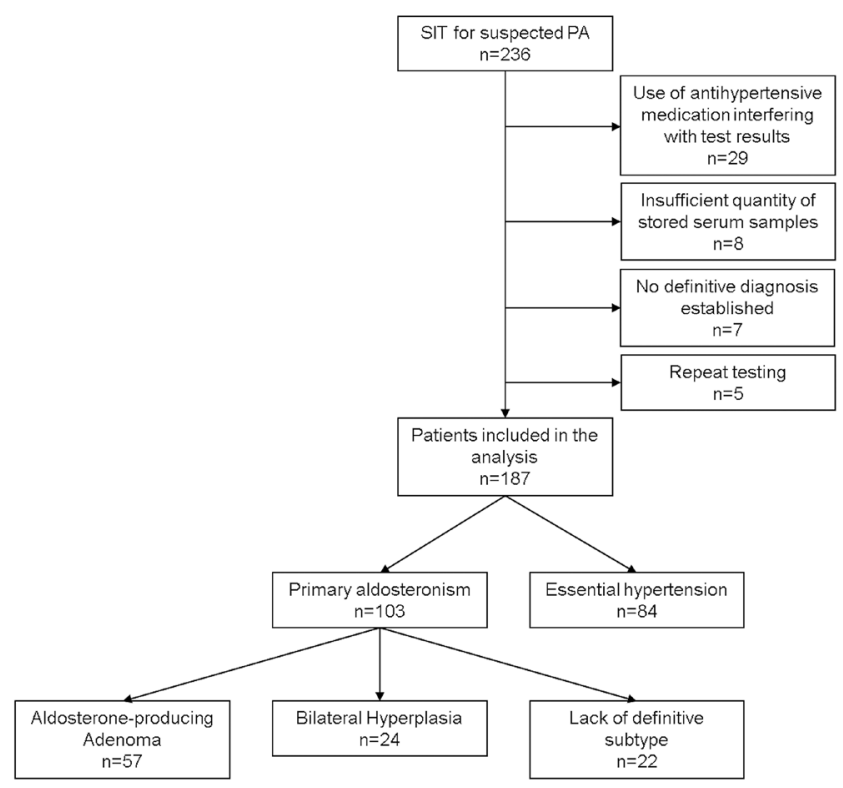

Figure 1

Study flow: 236 patients underwent saline infusion testing (SIT) for suspected primary aldosteronism (PA). 187 patients were included in the final analysis. Unknown = subtype of PA not known due to unsuccessful adrenal vein sampling or patient's refusal to undergo adrenal vein sampling or surgery. 
no definitive diagnosis after initial workup $(n=7)$. The clinical characteristics of the 187 included patients are given in Table 1.

Diagnosis of PA as well as subtype was determined according to the Endocrine Society Practice Guideline (1) taking into account clinical presentation, results of SIT by using IA in clinical routine, preoperative imaging, adrenal vein sampling (AVS), adrenal pathology, as well as therapeutic outcome (i.e. of surgical or medical treatment). An aldosterone cut-off at $4 \mathrm{~h}$ after saline infusion of 50 $\mathrm{ng} / \mathrm{L}$ measured by IA was used to confirm presence of PA in patients with positive screening criteria. Records of patients with an aldosterone concentration between 37 and $70 \mathrm{ng} / \mathrm{L}(n=38)$ were reviewed independently by two experienced endocrinologists to determine diagnosis of PA. Cases, in which both endocrinologists differed in their assessment, were discussed by a broader panel of endocrinologists. If no consensus regarding final diagnosis could be reached, patients were excluded from the analysis $(n=7)$. In patients with PA willing to undergo surgery, AVS without cosyntropin was performed to differentiate unilateral from bilateral PA (diagnostic criteria during AVS: selectivity index $\geq 2$, lateralization index $\geq 4: 1$, or $\geq 3: 1$ and contralateral suppression).

\section{Routine measurements of aldosterone and renin by immunoassay}

All samples were measured at the clinical laboratory of the Department of Endocrinology and Diabetes of the
University Hospital Würzburg. Until September 2014 ( $n=81,43.3 \%)$, serum aldosterone was determined by Coat-a-Count ${ }^{\circledR}$ RIA ( Siemens), and plasma renin concentration with a Renin III Generation RIA (Cisbio). Starting in October $2014(n=106,56.7 \%)$ serum aldosterone and plasma renin concentrations were analyzed - after a comprehensive cross-validation - by an automated chemiluminescence immunoassay (CLIA, iSYS, Immuno Diagnostic Systems).

\section{LC-MS/MS-based measurement of aldosterone and additional gluco-/mineralocorticoids}

Measurement of aldosterone in SIT samples was performed in October 2019 by LC-MS/MS using a Sciex 6500+ QTRAP (SCIEX, Framingham, USA) MS-system linked with an Agilent 1290 UHPLC-system (G4226A autosampler, InfinityBinPump, G1316C column-oven, G1330B thermostat) as described previously (23). Analysis was performed with the MassChrom-Steroids in Serum kit (Chromsystems, Gräfelfing) and corresponding isotope standards according to the manufacturer's instruction. After off-line solid phase extraction of $500 \mu \mathrm{L}$ serum, $15 \mu \mathrm{L}$ of the eluted sample were used for analysis. Concentrations were calculated with Analyst Software (1.6.3) via 6 point calibration and $1 / \mathrm{x}$ weighting. Lower limits of quantification (LLOQ): aldosterone $(10 \mathrm{ng} / \mathrm{L})$, cortisol $(0.15 \mu \mathrm{g} / \mathrm{dL})$, cortisone $(0.15 \mu \mathrm{g} / \mathrm{L})$, corticosterone $(0.175 \mu \mathrm{g} / \mathrm{L}), \quad$ 11-deoxycorticosterone $(0.023 \mu \mathrm{g} / \mathrm{L})$, 11-deoxycortisol $(0.03 \mu \mathrm{g} / \mathrm{L})$, 21-deoxycortisol $(0.027 \mu \mathrm{g} / \mathrm{L})$,

Table 1 Clinical characteristics of study cohort. Data are given as mean \pm S.D., $n$ (\%) or median (interquartile range). Serum aldosterone (ALD) concentration was measured after adaptation of blood pressure medication for SIT. Comparisons were performed with Pearson chi-square for categorical variables, $t$-test for mean comparison of normally distributed data, Mann-Whitney U-test for non-normally distributed numerical variables.

\begin{tabular}{|c|c|c|}
\hline & PA & EH \\
\hline$n$ & 103 & 84 \\
\hline Age, years & $53 \pm 12$ & $52 \pm 13$ \\
\hline Male, $n(\%)$ & $66(64 \%)$ & $28(33 \%)$ \\
\hline $\mathrm{BMI}, \mathrm{kg} / \mathrm{m}^{2}$ & $29.1(21.1-32.5)$ & $26.1(23.9-29.2)$ \\
\hline Systolic BP, mmHg & $158(143-168)$ & $150(140-163)$ \\
\hline Diastolic BP, mmHg & $92(85-98)$ & $85(80-92)$ \\
\hline Diabetes & $21(20.4 \%)$ & $4(4.8 \%)$ \\
\hline Coronary heart disease & $5(4.9 \%)$ & $2(2.4 \%)$ \\
\hline Stroke & $5(4.9 \%)$ & $2(2.4 \%)$ \\
\hline Renal insufficiency & $8(7.85)$ & $2(2.4 \%)$ \\
\hline Sleep apnea syndrome & $6(5.8 \%)$ & $3(3.6 \%)$ \\
\hline Potassium, mmol/L & $3.9(3.4-4.1)$ & $4.3(4-4.5)$ \\
\hline Potassium substitution & $56(54.4 \%)$ & $10(11.9 \%)$ \\
\hline Serum ALD conc., ng/L & $237(153-360)$ & $90(57-139)$ \\
\hline Plasma renin conc., ng/L & $3.1(1.7-5.1)$ & $3.8(2.1-7.1)$ \\
\hline
\end{tabular}

$\begin{array}{r}\hline \text { P-value } \\ \hline \\ 0.409 \\ <0.001 \\ <\mathbf{0 . 0 0 1} \\ \mathbf{0 . 0 0 3} \\ \mathbf{0 . 0 0 4} \\ \mathbf{0 . 0 0 2} \\ 0.375 \\ 0.375 \\ 0.103 \\ 0.474 \\ <\mathbf{0 . 0 0 1} \\ <\mathbf{0 . 0 0 1} \\ <\mathbf{0 . 0 0 1} \\ \mathbf{0 . 0 1 4} \\ \hline\end{array}$

\begin{tabular}{c}
\hline APA \\
\hline 56 \\
$52 \pm 11$ \\
$34(61 \%)$ \\
$28.4(25.4-31.2)$ \\
$155(143-165)$ \\
$93(85-100)$ \\
$10(17.9 \%)$ \\
$2(3.6 \%)$ \\
$2(3.6 \%)$ \\
$3(5.4 \%)$ \\
$1(1.8 \%)$ \\
$3.7(3.3-4.0)$ \\
$36(64.3 \%)$ \\
$214(157-356)$ \\
$3.5(2.0-5.5)$ \\
\hline
\end{tabular}

\begin{tabular}{c}
\hline BAH \\
\hline 24 \\
$52 \pm 9$ \\
$16(67 \%)$ \\
$32.4(28.1-36.0)$ \\
$160(150-180)$ \\
$92(85-97)$ \\
$6(25.0 \%)$ \\
$2(8.3 \%)$ \\
$2(8.3 \%)$ \\
$2(8.3 \%)$ \\
$3(12.5 \%)$ \\
$3.9(3.7-4.1)$ \\
$13(54.1 \%)$ \\
$259(139-384)$ \\
$3.1(1.6-4.2)$ \\
\hline
\end{tabular}

\begin{tabular}{c}
\hline P-value \\
\hline \\
0.900 \\
0.614 \\
$\mathbf{0 . 0 0 2}$ \\
0.408 \\
0.505 \\
0.464 \\
0.370 \\
0.370 \\
0.614 \\
0.103 \\
$\mathbf{0 . 0 3 0}$ \\
$\mathbf{0 . 0 1 8}$ \\
0.741 \\
0.404
\end{tabular}

BP, blood pressure; conc., concentration. 
dihydrotestosterone (42 ng/L), androstenedione (0.022 $\mu \mathrm{g} / \mathrm{L})$, progesterone $(0.03 \mu \mathrm{g} / \mathrm{L})$, dehydroepiandrosterone $(0.229 \mu \mathrm{g} / \mathrm{L})$, dehydroepiandrosteronesulfate $(2.44 \mu \mathrm{g} /$ $\mathrm{dL})$, estradiol $(20 \mathrm{ng} / \mathrm{L})$, testosterone $(0.005 \mu \mathrm{g} / \mathrm{L})$ and 17a-hydroxyprogesterone (0.04 $\mu \mathrm{g} / \mathrm{L})$. Furthermore, 18-hydroxycorticosterone was ascertained to be base line separated from aldosterone (Supplementary Fig. 1, see section on supplementary materials given at the end of this article). Correctness of measurements was monitored by commercial quality controls and periodic participation in ring trials.

\section{Statistical analysis}

Statistical analysis was performed using SPSS version 25 (IBM Corp.) and MedCalc version 19.3. Aldosterone values below LLOQ ( $<10 \mathrm{ng} / \mathrm{L}$ for LC-MS/MS, $<37 \mathrm{ng} / \mathrm{L}$ for IA) were replaced by the following formula using Excel 2010 (Microsoft): $\mathrm{c}=\mathrm{LLOQ} / \sqrt{ } 2$ (random number between 0.75 and 1.5) as previously described (29). Clinical characteristics are presented as means \pm standard deviation for normally distributed parameters and medians and interquartile range for non-normally distributed variables. Comparisons were performed with Pearson Chi-Square for categorical variables, $t$-test for mean comparison of normally distributed data, MannWhitneyU-test for non-normally distributed numerical variables, and Wilcoxon test for paired samples. For comparison of different aldosterone assays, BlandAltman analysis was performed. Correlations were tested both by Pearson and Spearman test. To determine LC-MS/MS specific cut-offs, receiver operating characteristic (ROC) curves, positive/negative likelihood ratios and predictive values were calculated. We decided to use a positive predictive value of $90 \%$ as the criterion for confirmation of PA. The prevalence of PA in our cohort is $55 \%$ and hence typical for a tertiary reference center. A $P$-value $<0.05$ was considered statistically significant. To analyze relative changes of different steroids during SIT we calculated fold changes using the following equation:

hormone concentration after $4 \mathrm{~h}$ FC = hormone concentration after $4 \mathrm{~h}$ / hormone concentration at baseline

To evaluate the usefulness of steroid profiles for differentiation of unilateral and bilateral PA, principal component analysis (PCA) and partial least square discriminant analysis (PLS-DA) were performed using MetaboAnalyst 4.0, as previously described (30).

\section{Results}

\section{Clinical characteristics}

Out of 187 patients included into the study, 103 patients were diagnosed with $\mathrm{PA}$, whereas 84 patients were diagnosed with EH (Fig. 1 and Table 1). Patients with PA were more often male, showed significantly higher BMI and blood pressure, higher prevalence of diabetes, lower potassium, higher aldosterone concentrations, and lower renin levels compared to EH (Table 1). No significant differences between the two groups were observed regarding age and comorbidities such as coronary heart disease, stroke, sleep apnea syndrome, and renal insufficiency (Table 1). Subtype differentiation of patients with PA was available for 80 patients. Characteristics of patients with APA and BAH are shown in Table 1. We furthermore retrospectively applied the PASO outcome criteria (31): 46 patients underwent adrenalectomy, 31 had sufficient follow- up (6-102 months). Out of these, 13 had complete, 14 had partial and 4 had absent clinical success. Twenty-eight had complete biochemical success and three absent biochemical success.

\section{Comparison of radioimmunometric assay and chemiluminescence immunoassay}

Over the course of the study, two different IAs were used for aldosterone measurement (RIA, $n=81$ (43\%); CLIA, $n=106(57 \%))$. Table 2 shows aldosterone concentrations during SIT measured by either RIA or CLIA. Aldosterone concentrations from both tests were similar in patients with EH, APA and BAH before and after saline infusion. When cases of APA and BAH were combined, median aldosterone concentration after saline infusion was significantly different (171 ng/L by RIA vs $120 \mathrm{ng} / \mathrm{L}$ by CLIA, $P=0.027)$. As expected, patients with PA showed significantly higher aldosterone concentrations during SIT than patients with $\mathrm{EH}$, and this was true for both assays. No significant differences in aldosterone could be detected between patients with APA and BAH.

\section{Comparison of immunoassays and LC-MS/MS}

Similar to RIA and CLIA, aldosterone concentrations during SIT determined by LC-MS/MS were significantly higher in PA than in EH (172 vs $83 \mathrm{ng} / \mathrm{L}$ before and 126 vs $33 \mathrm{ng} / \mathrm{L}$ after saline infusion; both $P<0.001)$. In contrast, aldosterone levels at both time points did not differ significantly between patients with APA and BAH (Table 3). 
Table 2 Comparison of different immunoassays. Median aldosterone concentration before $(0 \mathrm{~h})$ and after ( $4 \mathrm{~h})$ saline infusion by RIA $(n=81)$ and chemoluminescence assay (CLIA, $n=106)$. Data are given as median and interquartile range. PA subtypes (APA and $\mathrm{BAH}$ ) were not definitively determined in 22 patients with PA.

\begin{tabular}{|c|c|c|c|c|c|c|c|}
\hline & \multirow[b]{3}{*}{$\boldsymbol{n}$} & \multicolumn{6}{|c|}{ Aldosterone $(\mathrm{ng} / \mathrm{L})$ during the SIT } \\
\hline & & \multicolumn{3}{|c|}{$\mathrm{Oh}$} & \multicolumn{3}{|c|}{$4 \mathrm{~h}$} \\
\hline & & Coat-a-count $\circledast$ RIA & IDS-iSYS aldosterone ${ }^{\circledR}$ CLIA & $P$-value & Coat-a-count $\circledast \mathrm{RIA}$ & IDS-iSYS aldosterone ${ }^{\circledR}$ CLIA & $P$-value \\
\hline $\mathrm{EH}$ & 84 & $92(71-131)$ & $86(44-146)$ & 0.414 & $33(25-48)$ & $37(37-40)$ & 0.195 \\
\hline PA & 103 & $210 *(147-313)$ & $265 *(158-384)$ & 0.235 & $120 *(80-190)$ & $171 *(101-246)$ & 0.027 \\
\hline APA & 57 & 192 (146-367) & 269 (183-376) & 0.092 & $154(77-191)$ & 175 (119-329) & 0.109 \\
\hline $\mathrm{BAH}$ & 24 & 153 (139-292) & $276(157-387)$ & 0.290 & $111(79-154)$ & $171(98-242)$ & 0.108 \\
\hline
\end{tabular}

*P $<0.001$ vs EH (Mann-WhitneyU-test).

APA, aldosterone-producing adenoma (RIA: $n=23$, CLIA: $n=34$ ); BAH, bilateral adrenal hyperplasia (RIA: $n=9$, CLIA: $n=15$ ); EH, essential hypertension (RIA: $n=37$, CLIA: $n=47) ;$ PA, primary aldosteronism (RIA: $n=44, \mathrm{CLIA}: n=59$ ).

Only two patients presented with aldosterone after saline infusion below the LC-MS/MS LLOQ of $10 \mathrm{ng} / \mathrm{L}$ in comparison to 54 patients with values below the IA LLOQ of $37 \mathrm{ng} / \mathrm{L}$ (all $\mathrm{EH})$. Median aldosterone concentrations measured by LC-MS/MS were significantly lower compared to IA $(P<0.01)$ for baseline samples in EH, PA, APA and BAH, Fig. 2A, B and Table 3; $P<0.01$ for post-infusion samples of PA, APA, and BAH, Fig. $2 \mathrm{C}$ and D). Similar results were obtained, when comparing patients measured by RIA or CLIA to LC-MS/MS (Supplementary Figs 2 and 3). IA and LC-MS/MS measurements of aldosterone showed good linear correlation (Spearman correlation coefficient 0.876, Pearson $\mathrm{r}$ coefficient 0.930, both $P<0.001$ ) independent of the IA used (RIA/CLIA) (Fig. 3). Bland-Altman plot demonstrated IA-based aldosterone values to be on average $31 \mathrm{ng} / \mathrm{L}$ higher than LC-MS/MS (data not shown) with slightly lower deviation of RIA (22 ng/L) compared to CLIA (38 ng/L) (Fig. 3).

\section{Determination of an LC-MS/MS-specific aldosterone threshold}

The aldosterone cut-off was determined by ROC analysis of post SIT aldosterone for diagnosis of PA (Fig. 4). Sensitivity, specificity, likelihood ratios and predictive values of different aldosterone cut-offs are given in Tables 4 and 5. Instead of calculating the frequently used Youden's index that equally weighs sensitivity and specificity, we decided to use a positive predictive value of $90 \%$ as criterion. This approach led to an optimal aldosterone cut-off of $54 \mathrm{ng} / \mathrm{L}$ for IA and $69 \mathrm{ng} / \mathrm{L}$ for LC/MS-MS, respectively (Tables 4 and 5). Application of the aldosterone cut-off of $69 \mathrm{ng} / \mathrm{L}$ for LC-MS/MS led to a misclassification of 31 out of 187 patients (16.6\%): nine patients with $\mathrm{EH}$ were falsely classified as PA, whereas in 22 patients diagnosis of PA (APA: $n=9$, BAH: $n=8$, unknown subtype: $n=5$ ) would have been missed. In contrast, only five patients were falsely classified as EH instead of PA, using an aldosterone cut-off of $54 \mathrm{ng} / \mathrm{L}$ for IA.

\section{Dynamics of steroid panel testing during SIT and its value for PA diagnosis}

To understand the dynamics of aldosterone precursors after saline infusion, we explored changes of 11-deoxycorticosterone, 21-deoxycortisol, 11-deoxycortisol, corticosterone, cortisol and cortisone before and after SIT (Fig. 5). We found a significant decrease of all analytes before vs after SIT (all $P<0.001$ ) and statistically significant higher concentrations of

Table 3 Aldosterone concentrations during saline infusion testing measured by immunoassay and LC-MS/MS. Median aldosterone concentration before $(0 \mathrm{~h})$ and after $(4 \mathrm{~h})$ saline infusion measured by immunoassay and LC/MS-MS. PA subtypes (APA and BAH) were not definitively determined in 22 patients with PA.

\begin{tabular}{|c|c|c|c|c|c|}
\hline & \multirow[b]{3}{*}{$n$} & \multicolumn{4}{|c|}{ Aldosterone (ng/L) during the SIT } \\
\hline & & \multicolumn{2}{|c|}{$\mathrm{Oh}$} & \multicolumn{2}{|c|}{$4 \mathrm{~h}$} \\
\hline & & Immunoassay & LC-MS/MS & Immunoassay & LC-MS/MS \\
\hline $\mathrm{EH}$ & 84 & $90(57-139)$ & $83(53-128)$ & $37(30-44)$ & $33(24-48)$ \\
\hline PA & 103 & $237 *(153-360)$ & $172 *(99-271)$ & $154 *(89-218)$ & $126 *(72-187)$ \\
\hline APA & 57 & $229(156-367)$ & $187(113-280)$ & $166(85-242)$ & $139(90-223)$ \\
\hline $\mathrm{BAH}$ & 24 & $247(142-368)$ & $152(97-301)$ & $136(87-194)$ & $113(59-159)$ \\
\hline
\end{tabular}



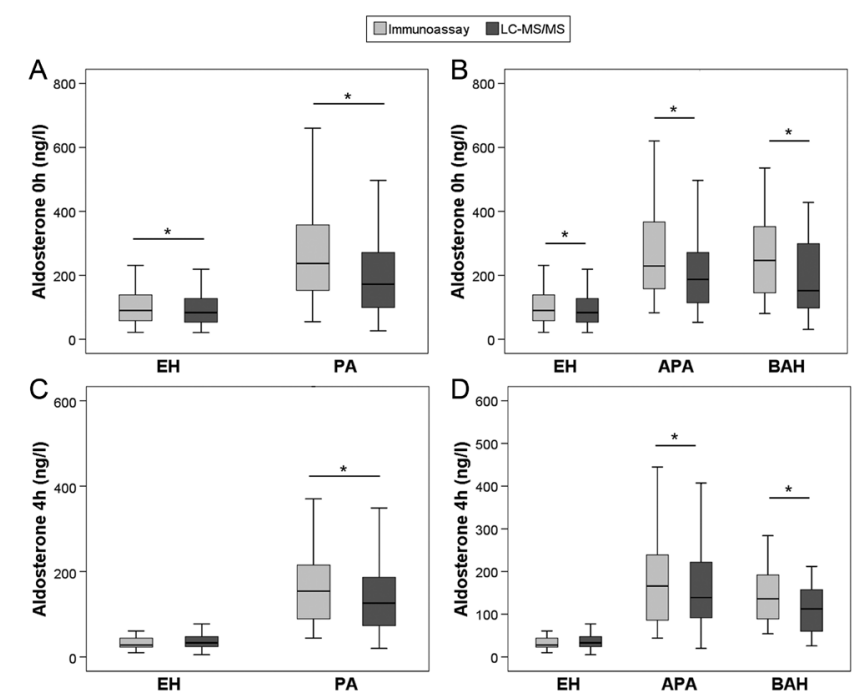

\section{Figure 2}

Aldosterone concentrations measured by immunoassay and

LC-MS/MS during saline infusion testing in patients with essential hypertension ( $\mathrm{H}, \mathrm{A}, \mathrm{B}, \mathrm{C}$ and $\mathrm{D}$ ), primary aldosteronism (PA, $A$ and $C$ ), aldosterone-producing adenoma (APA, B and D) and bilateral adrenal hyperplasia (BAH, B and $D)$ before ( $0 \mathrm{~h}, \mathrm{~A}$ and $\mathrm{B})$ and $\operatorname{after}(4 \mathrm{~h}, \mathrm{C}$ and $\mathrm{D})$ saline infusion. * $P<0.01$ (Wilcoxon test).

11-deoxycorticosterone in post-SIT samples from PA compared to $\mathrm{EH}$ patients $(P<0.001)$, whereas no differences in fold changes of all other steroids could be detected. Accordingly, none of these analytes was of similar diagnostic value as aldosterone alone. We furthermore performed principal compound analysis (PCA) and partial least square discriminant analysis (PLS-DA) for differentiation between PA and EH (Fig. 6A and B) as well as APA and BAH (Fig. 6C and D) based on steroid profiles after saline infusion and did not find improved discrimination by measurement of additional steroids.

\section{Discussion}

The low positive predictive value of screening for PA using ARR leads to the necessity of confirmatory testing (1). Positive confirmatory test results pave the way for invasive workup and surgery which may cure patients with APA (31, 32). To date, no 'gold standard' for case confirmation of PA has been established due to inconclusive results of several studies regarding diagnostic accuracy of, for example, saline infusion, captopril challenge, or fludrocortisone suppression $(9,33,34)$ and current guidelines do not
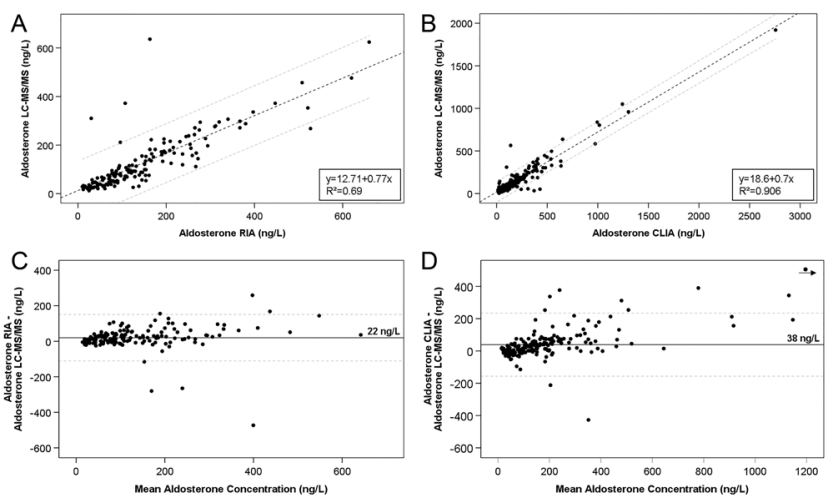

Figure 3

(A and B) Scatter plot of aldosterone concentrations measured by RIA ( $n=162)$, CLIA $(n=212)$ and LC-MS/MS. Dashed lines: 95\% confidence interval. (A) RIA: Spearman correlation coefficient $0.878(P<0.001)$, Pearson $r$ coefficient $0.833(P<$ 0.001). (B) CLIA: Spearman correlation coefficient $0.877(P<$ $0.001)$, Pearson $r$ coefficient $0.952(P<0.001)$. (C and D) Bland-Altman analysis of all aldosterone measurements by RIA (C, $n=162), C L I A(D, n=212)$ and LC-MS/MS. Continuous line: mean difference, dashed lines: $95 \%$ limits of agreement. For better visualization, $x$ - and $y$-axes were cut at $1200 \mathrm{ng} / \mathrm{L}$, excluding one single data point from the plot as marked by the dot and arrow in panel D.

express a specific recommendation for one particular test. By using oral sodium suppression and urinary aldosterone concentration as a measure of aldosterone exposure, it has been recently confirmed that there is a wide continuum of normal to relatively high and excessive aldosterone exposure in patients with hypertension (35). In our study we provide method-specific cut-offs that rely on the testing by IA and clinical judgment at the time of referral. Recumbent SIT is one of the most commonly used confirmatory tests in which serum aldosterone is measured after $4 \mathrm{~h}$ of saline infusion to detect aldosterone suppression or autonomous secretion (10) usually applying RIA or CLIA $(14,36)$. In the present work we evaluated highly sensitive measurement of aldosterone with different analytical techniques (i.e. LC-MS/MS, RIA and CLIA) and found - as already reported by others (17, $25,27)$ - that aldosterone concentrations measured by LC-MS/MS were generally lower than those derived from IA. Of note, however, assay-specific cut-offs for LC-MS/MS and IA- based on clinical diagnosis of PA were similar.

Few studies have evaluated the utility of LC-MS/MS for diagnosis (27) and confirmatory testing (28) of PA. With a representative cohort of 187 cases (PA, $n=103$; EH, $n=84$ ), this is the first large series to study aldosterone 
A
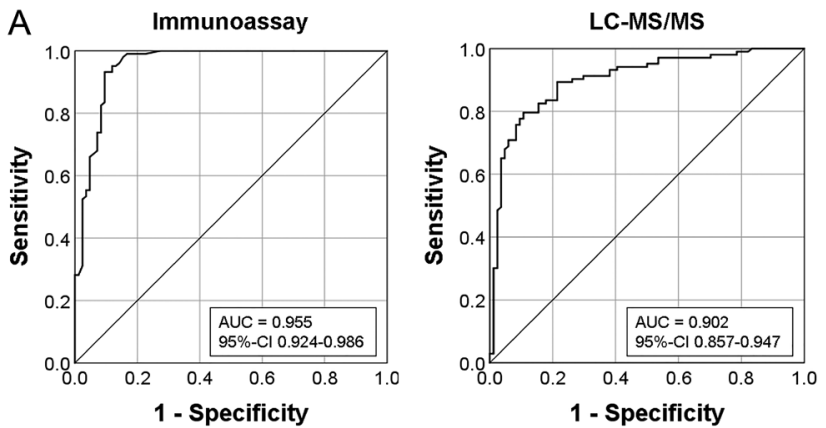

B

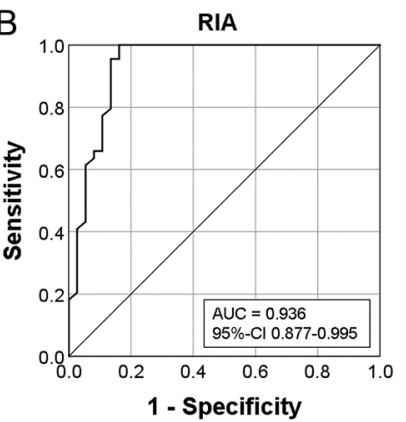

C
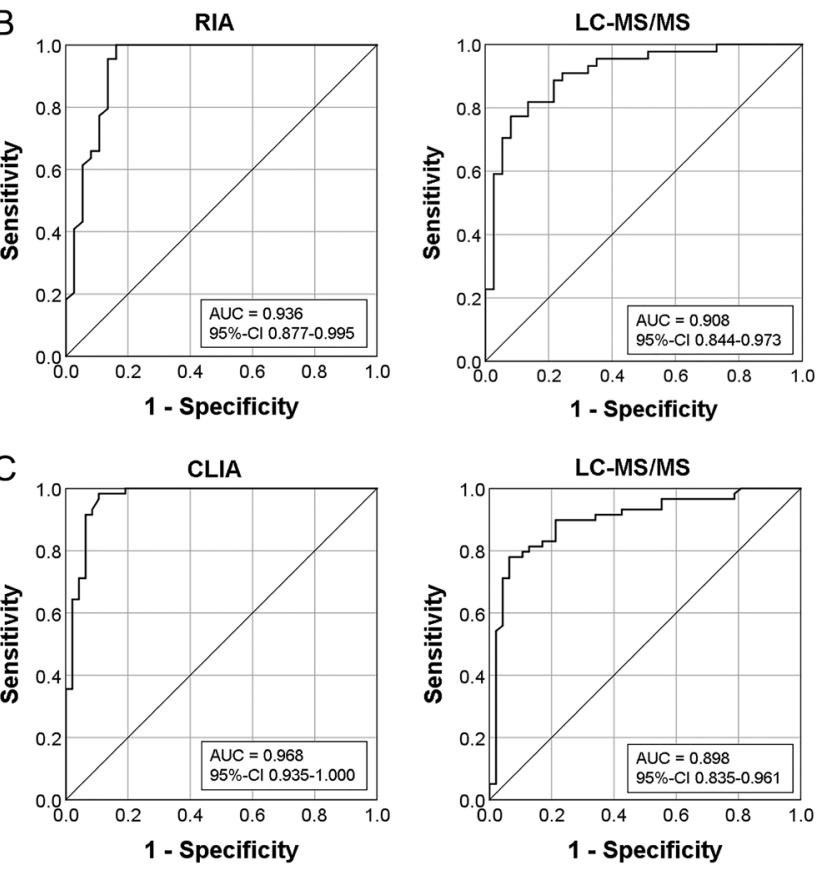

\section{Figure 4}

Receiver operating characteristics (ROC) curve for aldosterone concentrations after saline infusion measured by immunoassay and LC-MS/MS for detection of primary aldosteronism. AUC,area under the curve. $P<0.001$ for both ROC curves.

during SIT by LC-MS/MS. Within a relatively short time interval, this analytical methodology has found its way into diagnostic routine especially for the quantification of androgens and precursors $(37,38,39)$. Aldosterone is part of most established steroid panels and can be measured with sufficient sensitivity and precision to detect the low aldosterone concentrations present after saline infusion when state-of-the-art instrumentation and thorough validation is applied $(10,36,40)$. IA-based analysis of aldosterone is afflicted with specific shortcomings such as varying antibody specificity and antibody crossreactivity with structurally similar compounds which leads to overestimation of aldosterone (41). Previous

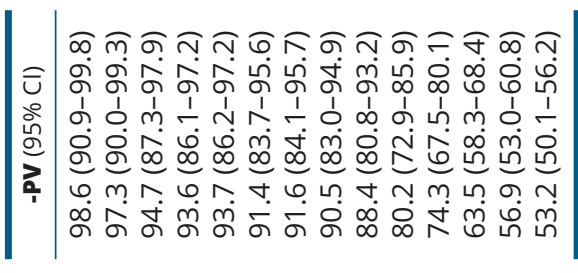

จุळ

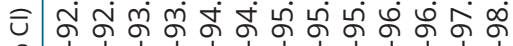

苞

岕

a

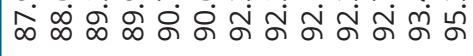

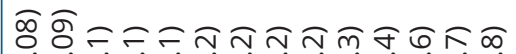

io ó ó ó ó ó ó ó ó

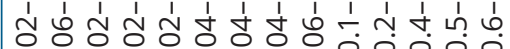

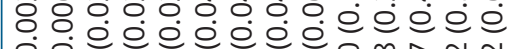

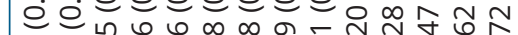

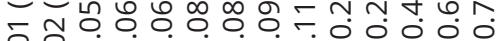

0.0.0.0.0.0.0.0.00000

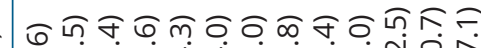

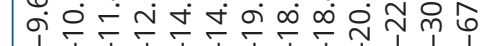

م.

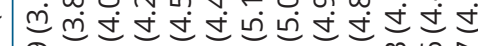

ウ̆

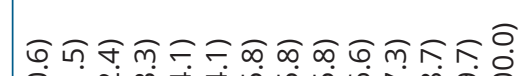

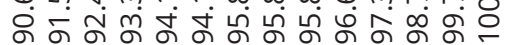

b남ำ

mं

$m$ Un

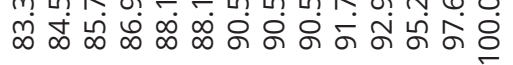

它

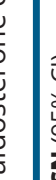

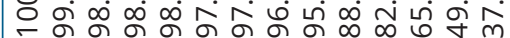

선

मं

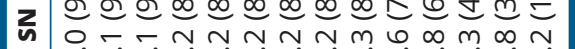

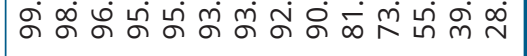




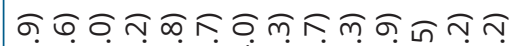
万̄ 1. 1 b

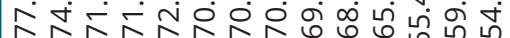

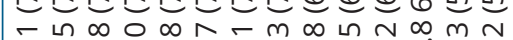

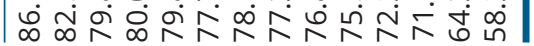

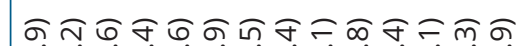

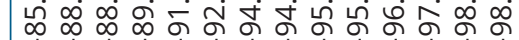

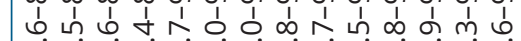

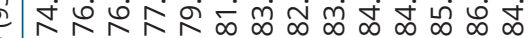
on m n N - o o t n -

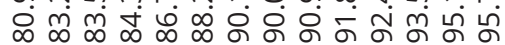

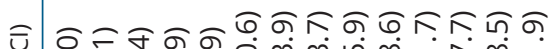
மi

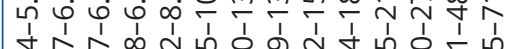
ปd ḋd

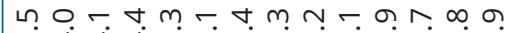

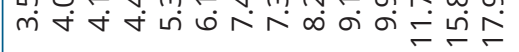

i i i i i i o i i i i i i o

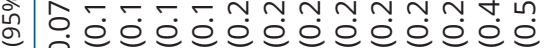

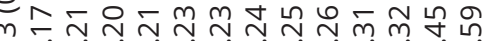

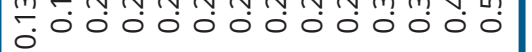

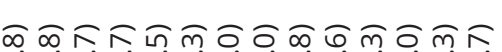

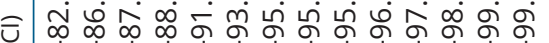

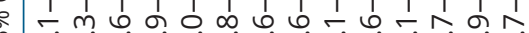
ற்

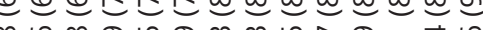
ํ. สุซ Є ம்

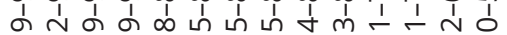

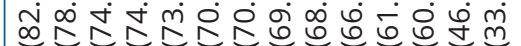

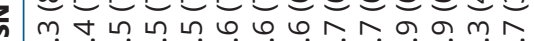

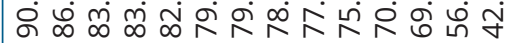
$\frac{0}{\sqrt{0}}$

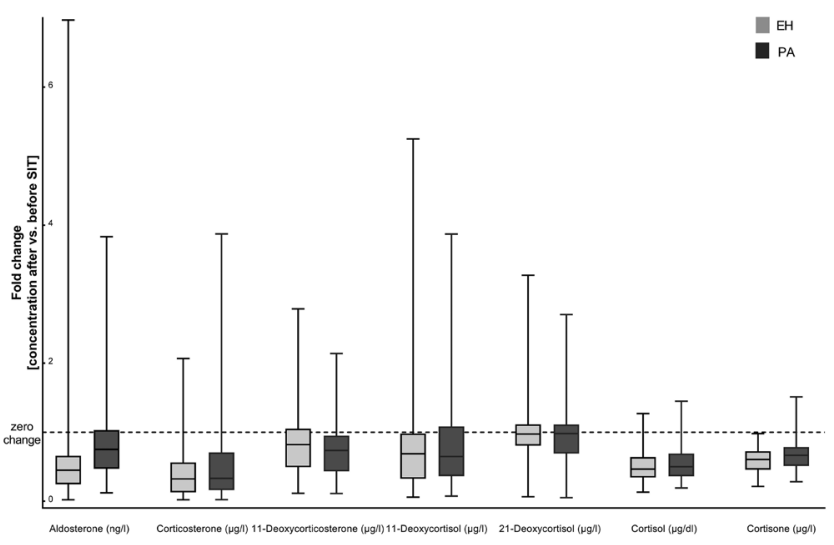

\section{Figure 5}

Fold changes (before vs after saline infusion) of steroids measured by LC-MS/MS during saline infusion testing in patients with essential hypertension ( $\mathrm{EH}, n=84)$ and primary aldosteronism (PA, $n=103$ ). Dashed line: no change in steroid concentration before vs after saline infusion.

studies reported significant variations between different IAs $(12,14,16)$. In our study, IA measurement was on average $31 \mathrm{ng} / \mathrm{L}$ higher than LC-MS/MS quantification, and this is well in line with previous reports despite good correlation $(28,42,43)$. Even by using highly sensitive and specific IAs like in this study, the lower limit of quantification is significantly higher in IA compared to LC-MS/MS. With the limits of quantification used here, aldosterone after SIT could be quantified in 372/374 samples with LC-MS/MS but only in 66/374 samples with IA. Optimal cut-off for LC-MS/MS of $69 \mathrm{ng} / \mathrm{L}$ reached a sensitivity of only $79 \%$ with a specificity of $89 \%$. This is in contrast to a recently published paper by Fries et al., in which the authors propose a lower LC-MS/MS cut-off for aldosterone after SIT compared to IA (44). To establish an LC-MS/MS specific cut-off for aldosterone during SIT the authors used two approaches sequentially: First, they developed a regression equation to determine LC-MS/MS cut-offs based on previously obtained IA results. Second, aldosterone was quantified by LC-MS/MS in samples from patients with $\mathrm{PA}$ and $\mathrm{EH}$ in their center and aldosterone suppression to $<83 \mathrm{pmol} / \mathrm{L}$ - the LLOQ of that laboratory - was found in $92.5 \%$ of $\mathrm{EH}$ patients. The latter cut-off was then validated in samples from the German Conn Registry. This study as well as in the analysis by Guo et al. (28) used the Youden Index as the criterion for cut-off development which equally takes into account sensitivity and specificity. In the present study we chose to base our cut-off on the criterion of a positive predictive value of $90 \%$ rather than the Youden Index. Using a positive 
A

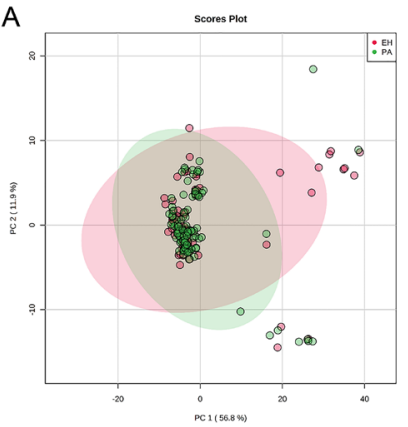

C

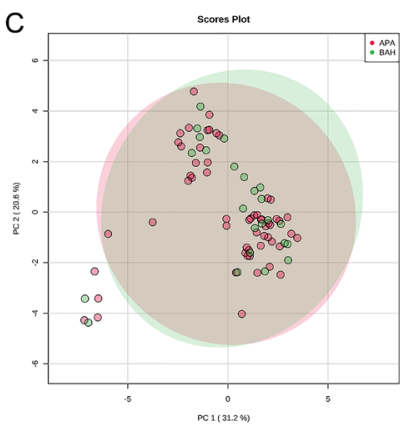

B

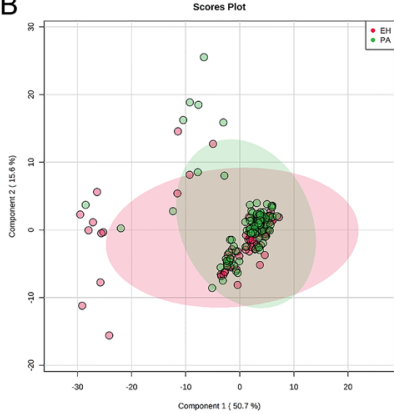

D

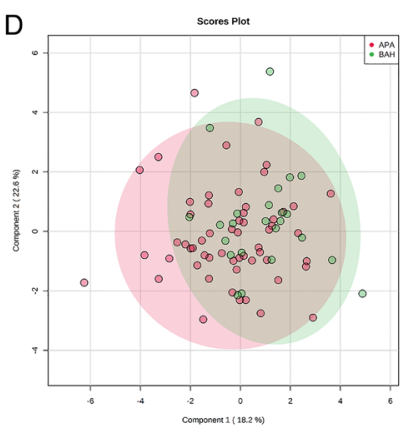

\section{Figure 6}

(A) Principal component analysis score plot for separation between primary aldosteronism (PA) and essential hypertension (EH) based on steroid profiles. (B) Partial least square - discriminant analysis score plot for separation between primary aldosteronism (PA) and essential hypertension (EH) based on steroid profiles. (C) Principal component analysis score plot for separation between unilateral (APA) and bilateral (BAH) primary aldosteronism based on steroid profiles. (D) Partial least square discriminant analysis score plot for separation between unilateral (APA) and bilateral (BAH) primary aldosteronism based on steroid profiles.

predictive value of $90 \%$, the LC-MS/MS cut-off in the study by Fries et al. would have been higher by $37 \mathrm{pmol} / \mathrm{L}$ compared to the one proposed using the Youden Index. Finally, differences in the case definitions between the studies as well as the increased sensitivity of our method likely contribute to the differences between the published studies and ours.

Our analyses of the course of further steroid hormones during SIT do not add any diagnostic value in decision making, even though 11-deoxycorticosterone was significantly higher in PA after SIT than in EH. However, we did not measure 18-oxocortisol and 18-hydroxycortisol, both representing hybrid steroids that show promise regarding non-invasive subtype differentiation in PA $(45,46)$.

Despite the higher accuracy of LC-MS/MS measurement and associated lower LC-MS/MS test results,

LC-MS/MS mis-classified nearly $17 \%$ of PA patients as unaffected by PA and falsely classified 5\% of essential hypertensives as having PA. This is most likely explained by the fact that aldosterone values $\geq 50 \mathrm{ng} / \mathrm{L}$ in IA were used to trigger further evaluation for PA.

Two main features of PA need to be taken into account when considering confirmatory testing:

(i) It is becoming increasingly clear that PA is part of a broad spectrum of disease ranging from physiologic, non-autonomous aldosterone secretion over the development of aldosterone producing cell clusters (47) to more severe forms of BAH and APAs. For the latter, disease-causing somatic mutations have been identified in the KCNJ5 (48), CACNA1D (49), ATP1A1 or ATP2B3 genes (50), which are clinically associated with a more severe phenotype and a higher prevalence of hypokalemia than in BAH (1). Specific subtypes of APA are associated with detectable concentrations of hybrid steroids 18-oxocortisol and 18-hydroxycortisol in peripheral blood and blood from AVS (46). They can be used diagnostically and are detectable at tissue level with mass spectrometry imaging (51) but most likely are synthesized at negligible quantities in nonAPA PA and therefore are of limited value in cases of low or borderline aldosterone excess. The broad disease spectrum is well reflected by the curbed run of the LC-MS/MS ROC curve.

(ii) Current clinical decision making and consequent diagnosis of PA usually relies on one single measurement of aldosterone during SIT. Since clinical decision making in our series was based on clinical evaluation, imaging results and a single IA test result it is not surprising that some cases with aldosterone concentrations after SIT at or slightly above the cut-off of $50 \mathrm{ng} / \mathrm{L}$ underwent further workup and finally PA was diagnosed. It is conceivable that repeated testing might have excluded PA in these cases and conversely some apparent $\mathrm{EH}$ patients indeed in the course of disease may develop PA. Hence, the arbitrary cut-off of $50 \mathrm{ng} / \mathrm{L}$ confounds the seemingly more convincing results of IA.

The case definition is a limitation of our study. Indeed it would be desirable to clinically confirm diagnosis during follow-up and perform repeat testing in borderline cases. Therefore we cannot exclude potential bias due to exclusion of patients with potentially interfering medication, repeat testing or unclear diagnosis. However, in a clinical setting this is unrealistic. A further limitation 
to the broad applicability of LC-MS/MS as used in our study is the relatively sensitive equipment used for aldosterone quantification during SIT. This may be different at some institutions due to higher LLOQ associated with the use of different instrumentation and test setup. The most critical drawbacks of the present study are, however, (i) the determination of diagnosis of PA based on IA results and (ii) the absence of a separate validation cohort.

In conclusion, the ideal diagnostic criterion for PA remains to be established and LC-MS/MS alone might not be the solution. Our study provides the basis to use this emerging method in clinical routine. At our center, we will consider aldosterone by LC-MS/ MS of $69 \mathrm{ng} / \mathrm{L}$ or higher to trigger further workup; in presence of lower results, we suggest to discuss the value of repeated testing with the patient to acknowledge the continuum of alterations in aldosterone secretion and the limited reliability of single hormone measurements. A prospective cohort with structured follow-up may help to decide which patients ultimately require complete PA workup and better define method-specific cut-offs for diagnosis.

\section{Supplementary materials}

This is linked to the online version of the paper at https://doi.org/10.1530/ EJE-20-0073.

\section{Declaration of interest}

Martin Fassnacht is a senior editor of the European Journal of Endocrinology. Martin Fassnacht was not involved in the peer review or editorial process for this paper on which he is listed as an author.

\section{Funding}

This research did not receive any specific grant from any funding agency in the public, commercial or not-for-profit sector.

\section{Data availability}

The datasets generated during and/or analyzed during the present study are not publicly available but are available from the corresponding author on reasonable request.

\section{Author contribution statement}

Conception/planning of the work: Matthias Kroiss, Stefanie Hahner, Carmina Teresa Fuss, Max Kurlbaum, Martin Fassnacht; contribution of patient data and samples: Timo Deutschbein, Stefanie Hahner, Carmina Teresa Fuss, Max Kurlbaum, Martin Fassnacht; laboratory analyses: Max Kurlbaum, Matthias Kroiss, Sabine Kendl; data analysis: Katharina Brohm, Carmina Teresa Fuss, Max Kurlbaum, Anke Hannemann; nterpretation of results: Carmina Teresa Fuss, Matthias Kroiss, Martin Fassnacht, Timo Deutschbein, Max Kurlbaum, Stefanie Hahner, Anke Hannemann; writing of the first paper draft: Carmina Teresa Fuss, Matthias Kroiss. All authors contributed to the critical interpretation of the results, reviewed the manuscript for important intellectual content, approved the final version of the manuscript, and have agreed to be accountable for his/her role in this manuscript.

\section{References}

1 Funder JW, Carey RM, Mantero F, Murad MH, Reincke M, Shibata H, Stowasser M \& Young Jr WF. The management of primary aldosteronism: case detection, diagnosis, and treatment: an Endocrine Society clinical practice guideline. Journal of Clinical Endocrinology and Metabolism 2016101 1889-1916. (https://doi. org/10.1210/jc.2015-4061)

2 Rossi GP, Bernini G, Caliumi C, Desideri G, Fabris B, Ferri C, Ganzaroli C, Giacchetti G, Letizia C, Maccario M et al. A prospective study of the prevalence of primary aldosteronism in 1,125 hypertensive patients. Journal of the American College of Cardiology 200648 2293-2300. (https://doi.org/10.1016/j.jacc.2006.07.059)

3 Hannemann A \& Wallaschofski H. Prevalence of primary aldosteronism in patient's cohorts and in population-based studies - a review of the current literature. Hormone and Metabolic Research 201244 157-162. (https://doi.org/10.1055/s-0031-1295438)

4 Born-Frontsberg E, Reincke M, Rump LC, Hahner S, Diederich S, Lorenz R, Allolio B, Seufert J, Schirpenbach C, Beuschlein F et al. Cardiovascular and cerebrovascular comorbidities of hypokalemic and normokalemic primary aldosteronism: results of the German Conn's Registry. Journal of Clinical Endocrinology and Metabolism 2009 94 1125-1130. (https://doi.org/10.1210/jc.2008-2116)

5 Hanslik G, Wallaschofski H, Dietz A, Riester A, Reincke M, Allolio B, Lang K, Quack I, Rump LC, Willenberg HS et al. Increased prevalence of diabetes mellitus and the metabolic syndrome in patients with primary aldosteronism of the German Conn's Registry. European Journal of Endocrinology 2015173 665-675. (https://doi.org/10.1530/ EJE-15-0450)

6 Rossi GP, Belfiore A, Bernini G, Desideri G, Fabris B, Ferri C, Giacchetti G, Letizia C, Maccario M, Mallamaci F et al. Prospective evaluation of the saline infusion test for excluding primary aldosteronism due to aldosterone-producing adenoma. Journal of Hypertension 200725 1433-1442. (https://doi.org/10.1097/ HJH.0b013e328126856e)

7 Rossi GP, Belfiore A, Bernini G, Desideri G, Fabris B, Ferri C, Giacchetti G, Letizia C, Maccario M, Mallamaci F et al. Comparison of the captopril and the saline infusion test for excluding aldosterone-producing adenoma. Hypertension $2007 \mathbf{5 0} 424-431$. (https://doi.org/10.1161/HYPERTENSIONAHA.107.091827)

8 Giacchetti G, Ronconi V, Lucarelli G, Boscaro M \& Mantero F. Analysis of screening and confirmatory tests in the diagnosis of primary aldosteronism: need for a standardized protocol. Journal of Hypertension $2006 \mathbf{2 4}$ 737-745. (https://doi.org/10.1097/01. hjh.0000217857.20241.0f)

9 Nanba K, Tamanaha T, Nakao K, Kawashima ST, Usui T, Tagami T, Okuno H, Shimatsu A, Suzuki T \& Naruse M. Confirmatory testing in primary aldosteronism. Journal of Clinical Endocrinology and Metabolism 201297 1688-1694. (https://doi.org/10.1210/jc.20112504)

10 Mulatero P, Monticone S, Bertello C, Mengozzi G, Tizzani D, Iannaccone A \& Veglio F. Confirmatory tests in the diagnosis of primary aldosteronism. Hormone and Metabolic Research 201042 406-410. (https://doi.org/10.1055/s-0029-1246186)

11 Heinrich DA, Adolf C, Quinkler M, Holler F, Lechner B, Nirschl N, Sturm L, Görge V, Beuschlein F \& Reincke M. Safety of medical adjustment and confirmatory testing in the diagnostic workup of primary aldosteronism. European Journal of Endocrinology 2019181 421-428. (https://doi.org/10.1530/EJE-19-0138) 
12 Schirpenbach C, Seiler L, Maser-Gluth C, Beuschlein F, Reincke M \& Bidlingmaier M. Automated chemiluminescenceimmunoassay for aldosterone during dynamic testing: comparison to radioimmunoassays with and without extraction steps. Clinical Chemistry 200652 1749-1755. (https://doi.org/10.1373/ clinchem.2006.068502)

13 Fischer E, Reuschl S, Quinkler M, Rump LC, Hahner S, Bidlingmaier M, Reincke M \& Participants of the German Conn's Registry - Else Kröner-Fresenius-Hyperaldosteronism R. Assay characteristics influence the aldosterone to renin ratio as a screening tool for primary aldosteronism: results of the German Conn's registry. Hormone and Metabolic Research 201345 526-531. (https:// doi.org/10.1055/s-0033-1343448)

14 Yin Y, Ma C, Yu S, Liu W, Wang D, You T, Cheng Q \& Qiu L. Comparison of three different chemiluminescence assays and a rapid liquid chromatography tandem mass spectrometry method for measuring serum aldosterone. Clinical Chemistry and Laboratory Medicine 201958 95-102. (https://doi.org/10.1515/cclm-2019-0706)

15 Fredline VF, Taylor PJ, Dodds HM \& Johnson AG. A reference method for the analysis of aldosterone in blood by high-performance liquid chromatography-atmospheric pressure chemical ionization-tandem mass spectrometry. Analytical Biochemistry 1997252 308-313. (https://doi.org/10.1006/abio.1997.2340)

16 Ray JA, Kushnir MM, Palmer J, Sadjadi S, Rockwood AL \& Meikle AW. Enhancement of specificity of aldosterone measurement in human serum and plasma using 2D-LC-MS/MS and comparison with commercial immunoassays. Journal of Chromatography: B, Analytical Technologies in the Biomedical and Life Sciences 2014970 102-107. (https://doi.org/10.1016/j.jchromb.2014.08.042)

17 Le Goff CM, Gonzalez-Antuña A, Peeters SD, Fabregat-Cabello N, Van Der Gugten JG, Vroonen L, Pottel H, Holmes DT \& Cavalier E. Migration from RIA to LC-MS/MS for aldosterone determination: implications for clinical practice and determination of plasma and urine reference range intervals in a cohort of healthy Belgian subjects. Clinical Mass Spectrometry 20189 7-17. (https://doi. org/10.1016/j.clinms.2018.06.002)

18 Fassnacht M, Arlt W, Bancos I, Dralle H, Newell-Price J, Sahdev A, Tabarin A, Terzolo M, Tsagarakis S \& Dekkers OM. Management of adrenal incidentalomas: European Society of Endocrinology Clinical Practice Guideline in collaboration with the European Network for the Study of Adrenal Tumors. European Journal of Endocrinology 2016 175 G1-G34. (https://doi.org/10.1530/EJE-16-0467)

19 Storbeck KH, Gilligan L, Jenkinson C, Baranowski ES, Quanson JL, Arlt W \& Taylor AE. The utility of ultra-high performance supercritical fluid chromatography-tandem mass spectrometry (UHPSFC-MS/MS) for clinically relevant steroid analysis. Journal of Chromatography: B, Analytical Technologies in the Biomedical and Life Sciences 20181085 36-41. (https://doi.org/10.1016/j. jchromb.2018.03.033)

20 Ketha H, Kaur S, Grebe SK \& Singh RJ. Clinical applications of LC-MS sex steroid assays: evolution of methodologies in the 21st century. Current Opinion in Endocrinology, Diabetes, and Obesity 201421 217-226. (https://doi.org/10.1097/MED.0000000000000068)

21 Hawley JM \& Keevil BG. Endogenous glucocorticoid analysis by liquid chromatography-tandem mass spectrometry in routine clinical laboratories. Journal of Steroid Biochemistry and Molecular Biology 2016 162 27-40. (https://doi.org/10.1016/j.jsbmb.2016.05.014)

22 Masjkur J, Gruber M, Peitzsch M, Kaden D, Di Dalmazi G, Bidlingmaier M, Zopp S, Langton K, Fazel J, Beuschlein F et al. Plasma steroid profiles in subclinical compared with overt adrenal Cushing syndrome. Journal of Clinical Endocrinology and Metabolism 2019104 4331-4340. (https://doi.org/10.1210/jc.2018-02349)

23 Schweitzer S, Kunz M, Kurlbaum M, Vey J, Kendl S, Deutschbein T, Hahner S, Fassnacht M, Dandekar T \& Kroiss M. Plasma steroid metabolome profiling for the diagnosis of adrenocortical carcinoma.
European Journal of Endocrinology 2019180 117-125. (https://doi. org/10.1530/EJE-18-0782)

24 Eisenhofer G, Peitzsch M, Kaden D, Langton K, Pamporaki C, Masjkur J, Tsatsaronis G, Mangelis A, Williams TA, Reincke M et al. Reference intervals for plasma concentrations of adrenal steroids measured by LC-MS/MS: impact of gender, age, oral contraceptives, body mass index and blood pressure status. Clinica Chimica Acta: International Journal of Clinical Chemistry 2017470 115-124. (https:// doi.org/10.1016/j.cca.2017.05.002)

25 Turpeinen U, Hämäläinen E \& Stenman UH. Determination of aldosterone in serum by liquid chromatography-tandem mass spectrometry. Journal of Chromatography: B, Analytical Technologies in the Biomedical and Life Sciences 2008862 113-118. (https://doi. org/10.1016/j.jchromb.2007.11.005)

26 Hinchliffe E, Carter S, Owen LJ \& Keevil BG. Quantitation of aldosterone in human plasma by ultra high performance liquid chromatography tandem mass spectrometry. Journal of Chromatography: B, Analytical Technologies in the Biomedical and Life Sciences 2013 913-914 19-23. (https://doi.org/10.1016/j. jchromb.2012.11.013)

27 Baron S, Amar L, Faucon AL, Blanchard A, Baffalie L, Faucard C, Travers S, Pagny JY, Azizi M \& Houillier P. Criteria for diagnosing primary aldosteronism on the basis of liquid chromatographytandem mass spectrometry determinations of plasma aldosterone concentration. Journal of Hypertension 201836 1592-1601. (https:// doi.org/10.1097/HJH.0000000000001735)

28 Guo Z, Poglitsch M, McWhinney BC, Ungerer JPJ, Ahmed AH, Gordon RD, Wolley M \& Stowasser M. Aldosterone LC-MS/MS assay-specific threshold values in screening and confirmatory testing for primary aldosteronism. Journal of Clinical Endocrinology and Metabolism 2018103 3965-3973. (https://doi.org/10.1210/jc.201801041)

29 Erlic Z, Kurlbaum M, Deutschbein T, Nölting S, Prejbisz A, Timmers HJ, Richter S, Prehn C, Weismann D, Adamski J et al. Metabolic impact of pheochromocytoma/paraganglioma: targeted metabolomics in patients before and after tumor removal. European Journal of Endocrinology 2019181 647-657. (https://doi.org/10.1530/ EJE-19-0589)

30 Xia J, Psychogios N, Young N \& Wishart DS. MetaboAnalyst: a web server for metabolomic data analysis and interpretation. Nucleic Acids Research 200937 W652-W660. (https://doi.org/10.1093/nar/gkp356)

31 Williams TA, Lenders JWM, Mulatero P, Burrello J, Rottenkolber M, Adolf C, Satoh F, Amar L, Quinkler M, Deinum J et al. Outcomes after adrenalectomy for unilateral primary aldosteronism: an international consensus on outcome measures and analysis of remission rates in an international cohort. Lancet: Diabetes and Endocrinology 20175 689-699. (https://doi.org/10.1016/S2213-8587(17)30135-3)

32 Miller BS, Turcu AF, Nanba AT, Hughes DT, Cohen MS, Gauger PG \& Auchus RJ. Refining the definitions of biochemical and clinical cure for primary aldosteronism using the primary aldosteronism surgical outcome (PASO) classification system. World Journal of Surgery 2018 42 453-463. (https://doi.org/10.1007/s00268-017-4311-1)

33 Willenberg HS, Vonend O, Schott M, Gao X, Blondin D, Saleh A, Rump LC \& Scherbaum WA. Comparison of the saline infusion test and the fludrocortisone suppression test for the diagnosis of primary aldosteronism. Hormone and Metabolic Research 201244 527-532.

34 Mulatero P, Milan A, Fallo F, Regolisti G, Pizzolo F, Fardella C, Mosso L, Marafetti L, Veglio F \& Maccario M. Comparison of confirmatory tests for the diagnosis of primary aldosteronism. Journal of Clinical Endocrinology and Metabolism 200691 2618-2623. (https:// doi.org/10.1210/jc.2006-0078)

35 Brown JM, Siddiqui M, Calhoun DA, Carey RM, Hopkins PN, Williams GH \& Vaidya A. The unrecognized prevalence of primary aldosteronism. Annals of Internal Medicine 2020173 10-20. (https:// doi.org/10.7326/M20-0065) 
36 Bayard F, Beitins IZ, Kowarski A \& Migeon CJ. Measurement of plasma aldosterone by radioimmunoassay. Journal of Clinical Endocrinology and Metabolism 197031 1-6. (https://doi.org/10.1210/jcem-31-1-1)

37 Vogeser M \& Parhofer KG. Liquid chromatography tandemmass spectrometry (LC-MS/MS) - technique and applications in endocrinology. Experimental and Clinical Endocrinology and Diabetes 2007115 559-570. (https://doi.org/10.1055/s-2007-981458)

38 Jannetto PJ \& Fitzgerald RL. Effective use of mass spectrometry in the Clinical Laboratory. Clinical Chemistry 201662 92-98. (https://doi. org/10.1373/clinchem.2015.248146)

39 Handelsman DJ \& Wartofsky L. Requirement for mass spectrometry sex steroid assays in the Journal of Clinical Endocrinology and Metabolism. Journal of Clinical Endocrinology and Metabolism 201398 3971-3973. (https://doi.org/10.1210/jc.2013-3375)

40 Tomaschitz A, Ritz E, Pieske B, Rus-Machan J, Kienreich K, Verheyen N, Gaksch M, Grübler M, Fahrleitner-Pammer A, Mrak P et al. Aldosterone and parathyroid hormone interactions as mediators of metabolic and cardiovascular disease. Metabolism: Clinical and Experimental 201463 20-31. (https://doi.org/10.1016/j.metabol.2013.08.016)

41 Burrello J, Monticone S, Buffolo F, Lucchiari M, Tetti M, Rabbia F, Mengozzi G, Williams TA, Veglio F \& Mulatero P. Diagnostic accuracy of aldosterone and renin measurement by chemiluminescent immunoassay and radioimmunoassay in primary aldosteronism. Journal of Hypertension 201634 920-927. (https://doi.org/10.1097/ HJH.0000000000000880)

42 Manolopoulou J, Fischer E, Dietz A, Diederich S, Holmes D, Junnila R, Grimminger P, Reincke M, Morganti A \& Bidlingmaier M. Clinical validation for the aldosterone-to-renin ratio and aldosterone suppression testing using simultaneous fully automated chemiluminescence immunoassays. Journal of Hypertension 201533 2500-2511. (https://doi.org/10.1097/HJH.0000000000000727)

43 Thuzar M, Young K, Ahmed AH, Ward G, Wolley M, Guo Z, Gordon RD, McWhinney BC, Ungerer JP \& Stowasser M. Diagnosis of primary aldosteronism by seated saline suppression test - variability between immunoassay and HPLC-MS/MS. Journal of Clinical Endocrinology and Metabolism 2020 105. (https://doi.org/10.1210/ clinem/dgz150)
44 Fries CM, Bae YJ, Rayes N, Sandner B, Isermann B, Stumvoll M, Fagotto V, Reincke M, Bidlingmaier M, Mandy V et al. Prospective evaluation of aldosterone LC-MS/MS-specific cutoffs for the saline infusion test. European Journal of Endocrinology 2020183 191-201. (https://doi.org/10.1530/EJE-20-0030)

45 Holler F, Heinrich DA, Adolf C, Lechner B, Bidlingmaier M, Eisenhofer G, Williams TA \& Reincke M. Steroid profiling and immunohistochemistry for subtyping and outcome prediction in primary aldosteronism-a review. Current Hypertension Reports 201921 77. (https://doi.org/10.1007/s11906-019-0985-0)

46 Eisenhofer G, Dekkers T, Peitzsch M, Dietz AS, Bidlingmaier M, Treitl M, Williams TA, Bornstein SR, Haase M, Rump LC et al. Mass spectrometry-based adrenal and peripheral venous steroid profiling for subtyping primary aldosteronism. Clinical Chemistry $2016 \mathbf{6 2}$ 514-524. (https://doi.org/10.1373/clinchem.2015.251199)

47 Omata K, Tomlins SA \& Rainey WE. Aldosterone-producing cell clusters in normal and pathological states. Hormone and Metabolic Research 201749 951-956. (https://doi.org/10.1055/s-0043-122394)

48 Choi M, Scholl UI, Yue P, Björklund P, Zhao B, Nelson-Williams C, Ji W, Cho Y, Patel A, Men CJ et al. K+ channel mutations in adrenal aldosterone-producing adenomas and hereditary hypertension. Science 2011331 768-772. (https://doi.org/10.1126/science.1198785)

49 Scholl UI, Goh G, Stölting G, de Oliveira RC, Choi M, Overton JD, Fonseca AL, Korah R, Starker LF, Kunstman JW et al. Somatic and germline CACNA1D calcium channel mutations in aldosteroneproducing adenomas and primary aldosteronism. Nature Genetics 201345 1050-1054. (https://doi.org/10.1038/ng.2695)

50 Beuschlein F, Boulkroun S, Osswald A, Wieland T, Nielsen HN, Lichtenauer UD, Penton D, Schack VR, Amar L, Fischer E et al. Somatic mutations in ATP1A1 and ATP2B3 lead to aldosteroneproducing adenomas and secondary hypertension. Nature Genetics 201345 440-444.e1. (https://doi.org/10.1038/ng.2550)

51 Sugiura Y, Takeo E, Shimma S, Yokota M, Higashi T, Seki T, Mizuno Y, Oya M, Kosaka T, Omura M et al. Aldosterone and 18-oxocortisol coaccumulation in aldosterone-producing lesions. Hypertension 201872 1345-1354. (https://doi.org/10.1161/ HYPERTENSIONAHA.118.11243)

Received 28 January 2020

Revised version received 16 October 2020

Accepted 20 October 2020 